\title{
The Present Situation and Future Prospect of Digital Library
}

\author{
Xin Zhang ${ }^{a}$, Dingli Song ${ }^{b}$, Fuxing $\mathrm{Yu}^{\mathrm{c}}$, Yina Suo ${ }^{\mathrm{d}}$ \\ Hebei United University, Tangshan, 063000, China \\ aemail: \\ sdlhr1006@sohu.com, bemail:sdlhr617@sohu.com, 'email:yfx626@126.com, ${ }^{d} e m a i l: 106492305 @$ \\ qq.com
}

Keywords: Digital Library; Cloud Computing; Mobile Library

\begin{abstract}
This paper finds out the problems emerging in development, through analysis of the present situation of the digital library construction in China. And, the solutions and developing mode prospect of future digital library are given.
\end{abstract}

\section{Introduction}

The library is an important platform for the public to get access to information. With the development of information technology, the traditional library and its operation management mode cannot meet the needs of the public. Especially in recent years, the rapid development of information technology, greatly promoted the technical research and practice of digital library.

Since 1988, the NSF's W. Wulf formally proposed the concept of "digital library" in the white paper about international cooperation, there has been more than 20 years. During the past 20 years, the digital library, from the virtual concept to the construction of the project, from the dominated by collection to the user-centered, has been gradually realized the orderly various information resources organization and sharing. It has expanded new field in theory research of information resources and the practice development [1].

\section{The Present Situation of the Digital Library Construction}

In the 1990s, the construction of digital library was been started. At the early stage, the construction didn't have a unified standard, which was because of the lack of national overall planning and unified coordination. Each unit just pursued the quantity of digital resources, rather than according to their own unit's collection features and the actual situation. It led to serious repetitive construction. At the same time, there was a big difference in each unit's digital library, such as user retrieval interface, retrieval language, etc. So, it was very difficult to connect each other. At the beginning of this century, the national and provincial governments promoted the co-construction and sharing of digital resources. By 2010, 31 provincial sub-centers, 2814 county branch centers and 458000 grassroots service outlets had been completed in the government's support and promotion, through the national cultural information resources sharing project. The national center had owned 100 TB of digital resources. National and municipalities are actively planning the resource sharing alliance of regional library digital. The digital library consortia integrates each unit's digital resources, realizing the complementary advantages, improving the capability and level of service for readers, achieving national and regional data resource sharing and coordinated development ${ }^{[2]}$.

In order to achieve a comprehensive and interactive mobile digital library service, it must be satisfied that users can retrieve and obtain resources at anytime, anywhere, conveniently, fast and low cost. However, to achieve this goal, it's necessary to solve the content, technology and cost problems, the China mobile digital library faced ${ }^{[3]}$.

Though, China's digital library has achieved great development and obtained great achievement, there are also many problems, with the development of technology and the improvement of readers' demands. 


\section{The Existing Problems of the Digital Library Construction}

Lack of basic theory construction. Digital library construction technology as an alien technology was introduced to China in 1996. The development of Chinese digital library technology mainly experienced three stages. During the first stage, from 1996 to 1998, China just introduced the concept of digital library, and the specific technical implementation, the scientific research and development are still in the bud stage. By six public libraries, owning some basis for the implementation, such as the nation library and the Beijing library, jointly launched the China experimental digital library construction project, which opened up the exploration and research of digital library in our country. During the second stage, from 1998 to 2001, China had made initial achievements in the digital library construction, developing a series of digital library systems development projects. Digital library research project institute, which was composed of Peking University, Tsinghua University, Northeast Normal University and other colleges and universities, raised a hot wave of digital library construction in our country, laying a solid foundation for the latter part of the library building. During the third stage, from2001 to now, the construction of digital library in our country has made some achievements, but many problems also has been exposed, especially lacking of basic theoretical construction. Throughout the history of digital library construction in China, in the research period of digital library construction, the development of simple technologies and systems was emphasized, and the establishment and development of the basic theories were ignored completely. It has a direct impact on our country in the future building endurance and limits the pace of the construction of digital libraries.

Serious waste of resources. Digital library construction is a complicated and huge engineering project, the implementation of each link and the construction will influence the development of the whole library. At the beginning of the construction, there were no ways to follow and no basic theory construction, which made a result of the lack of uniform standards and consistent building planning. So, each department cannot achieve unity in building awareness and balance. The every department of the digital library construction isn't consistent and the gap is quite large at present. At the same time, the purpose of the construction of each department is different, and the system integration is ignored. In addition, there is a large problem in resource integration, which is because of the lack of unified form and standard.

Islands of existing data center and low utilization rate of digital resources. Since last century digital library construction in full swing, many libraries, such as countries, municipalities and universities, are building a data center in a certain scale, which creates certain conditions for the preservation and utilization of data resources. However, the construction of each library lacks appropriate planning and coordination. There is no uniform standard of building database, creating a data island. The users are difficult to use the library data comprehensively. Data resource utilization rate is very low.

There are some common problems in the digital library construction in our country, such as unified digital library platform, the development imbalance of libraries, redundant construction, no interoperability among libraries, lacking of uniform standards and so on. With the advent of the era of the media, the library is faced with great challenge. With the emergence of various information terminals, the demands of users' convenience in getting access to information and the real-time are higher and higher. With the continuous development of information technology, it can become true.

Internet, mobile phones and television occupies the absolute route of transmission. In this context, the library combines with media, breaks through data islands and creates their own new world, which becomes the librarians' era pursuit.

\section{Technology Application and Development of Digital Library Based on Cloud Computing}

Cloud computing was first proposed by Eric Chmidt, the Google CEO, in 2006, when Google's business model was elaborated. Then, it's known widely. As an emerging field of research and application, it gets attention from academia and industry. In essence, cloud computing is a kind of distributed computing model. However, cloud computing greatly influences and changes the 
development of information technology industry, as a new computing mode. Many leading companies in the field of information technology such as Google, Microsoft and Ama-zon successively developed and launched fully functional, performance, powerful cloud computing public service platform. Through the cloud computing platform, they expanded business revenue model.

Computer and information technology field's researchers, as well as researchers in the field of library information, carry out extensive research on cloud computing from different angles. Libraries intelligence community at home and abroad about cloud computing research mainly includes three aspects: to define the meaning and characteristics of cloud computing and other basic theory; challenges brought to the library in information security and application mode by cloud computing; content of cloud computing in the application of libraries, the cloud computing model of digital libraries, etc. In particular, as an information technology infrastructure and computing architecture, cloud computing not only provides the basis for the construction of library's information system hardware and software platform, but also provides a new environment for the sustainable development of library's information work, especially provides referential research thought and technical reference for the construction of large-scale distributed digital library [4].

Cloud computing has five significant advantages: 1. Avoid upfront investment. Users use hardware and software resources, provided by cloud computing service provider, through renting. And they pay for them according to the use of computing resources and time-consuming. Thus, users can eliminate the investment necessary to build a computing environment hardware and system software. 2. Reduce operating costs. Cloud computing service providers can provide 7x24d real-time and reliable service, avoiding the local operating costs and staff to maintain the system. 3. Improve the system scalability. Cloud computing service providers can provide almost unlimited computing resources, the user can quickly expand or shrink the size of the system deployment according to demand. 4. Easy to access. Cloud computing services via the internet, users can get access to the internet services just through a PC or mobile device, such as a PAD or cell phone. 5 . Reduce business risks and maintenance costs. There is no need to purchase hardware and software equipment and personnel for system maintenance. So, users don't have to consider issues of software and hardware equipment depreciation, maintenance and upgrade. These reduce the investment of equipment maintenance costs and business risks [5].

Although cloud computing technology has important implications for library and information field, the application of cloud computing technology in the field are mainly concentrated on the use of cloud computing platform and service hosting library information system. By hosting digital library information system, library management system is no longer to be configured and maintained, reducing the cost of overall operating and system maintenance [6].

\section{Digital Library Development Prospect in the Future}

There are all kinds of information on the internet. It can be said that good and bad information are intermingled. Library information positioning should be knowledge and literature. With the growing popularity of the application and development of smart phones, IPAD, digital TV, digital telephone and other high-tech information terminals, people can swim in the ocean of information anytime, anywhere. On August 1, 2013, the state council issued the "broadband China" strategy and implementation plan, vigorously promoting the network connectivity and upgrading, achieving nationwide network signal coverage.

Future library anywhere in the world can be interconnected to form a sea of knowledge and literature, becoming an application platform which people can acquire knowledge and literature quickly, inexpensive, and efficiently. The platform integrates into the internet, becoming an important component of the internet.

By laptops, tablets, smart phones and electronic book reader and other mobile devices, people can read electronic books, electronic journals, electronic newspapers and various format video, audio, images, documents, which has become an essential way of life for people to obtain information, application and news. The retrieval at anytime and anywhere, easy to read and efficient 
low consumption mode of digital reading, are provided by the closely connection of mobile communication technology, internet and digital library, catering to the rhythm of modern people to pursue efficiency and simple life reading habits.

In the near future, with the continuous development of digital library, it will come into the information network of the sea. So, people can quickly and easily get needed information.

\section{Conclusion}

With the development of communication technology and service innovation, the service functions of digital library are enriched, which promoted the development of the digital library. People have access to the digital library through the intelligent mobile devices flexibly and conveniently, enjoying the mobile information service unrestricted by time, place and space, which will be the most important service form of future library. Although the mobile digital library is unable to provide more extensive and convenient services, because of the limited technology, with the development of mobile communication technology and the closer combination with the digital library, the more perfect mobile digital library services will be created.

\section{References}

[1] Jing Chen, Jianming Zheng. Research on the construction modes of foreign digital library [J]. Information and Documentation Services. 2011.5: 100.

[2] Lidong Huang. National new construction model of digital library [J]. Information and Documentation Services. 2013.2: 109.

[3] Zhihua Xiao. Research on the status and development strategy of mobile digital library [J]. Livrary Tribune. 2011.4: 31.

[4] Xueqin Tian. Progress and trends of library changes in cloud computing environment [J]. China Education Network. 2010.07: 21-25.

[5] Mingfang Yang, Xilin Yuan. Digital library in cloud computing environments [J]. Library Development. 2009.09: 36-38.

[6] Yifei Xue. Application of Cloud Computing in The Digital Library [J]. Science \& Technology Information. 2009.29: 372-373. 